\title{
Learning in the Digital Era - Awareness and Usage of Free Open Access Meducation among Emergency Department Doctors
}

\author{
Sashriqua Palliam ${ }^{1}$, Zeyn Mahomed ${ }^{1}$, Deidre Hoffman ${ }^{1}$, Abdullah E. Laher ${ }^{1}$ \\ 1. Emergency Medicine, University of the Witwatersrand, Johannesburg, ZAF
}

Corresponding author: Abdullah E. Laher, abdullahlaher@msn.com

\begin{abstract}
\section{Introduction}

Information and communication technology has revolutionized the space of medical education by providing a multitude of up-to-date evidence-based data to healthcare practitioners. Despite the increasing popularity of FOAM - Free Open Access Meducation (Medical Education) globally - data relating to its awareness and usage in Africa is lacking. In this study, we explore the awareness and usage of FOAM among doctors working at select emergency departments in Johannesburg.
\end{abstract}

\section{Methods}

The study comprised a prospective, questionnaire based, cross-sectional survey of medical doctors working at five academically affiliated emergency departments in Johannesburg. Data was described and compared.

\section{Results}

One-hundred and four participants completed the survey. Most of the respondents were aged between 31 and 39 years $(n=40,43.9 \%)$. There were no significant differences between the proportion of females and males that used FOAM ( $\mathrm{p}=0.56)$. Most participants $(\mathrm{n}=91,87.5 \%)$ were aware of FOAM, while $82(78.8 \%)$ used FOAM, 13 (12.5\%) were unsure if they used FOAM and nine (8.7\%) did not use FOAM. Majority of those that used FOAM, only used it once a week $(n=47,57.3 \%)$. Most participants spent between one and two hours per day on FOAM $(n=29,35.4 \%)$. Smartphones were by far the most commonly used device to access FOAM $(n=91,87.5 \%)$.

\section{Conclusion}

The level of awareness of FOAM is high and its usage is prevalent among emergency medicine healthcare professionals in Johannesburg. As technology becomes more prominent, institutions must aim to adapt to the digital era in their teaching methods.

Received 11/18/2019

Review began 11/18/2019

Review ended 11/20/2019

Published 11/24/2019

(๑) Copyright 2019

Palliam et al. This is an open access

article distributed under the terms of the Creative Commons Attribution License CC-BY 3.0., which permits unrestricted use, distribution, and reproduction in any medium, provided the original author and source are credited.

Categories: Emergency Medicine, Medical Education

Keywords: foam, free open access meducation, free open access medical education, digital medicine, emergency medicine, medical education

\section{Introduction}

"If you want to know how we practiced medicine 5 years ago, read a textbook. If you want to know how we practiced medicine 2 years ago, read a journal. If you want to know how we practice medicine now, go to a good conference. If you want to know how we will practice medicine in the future, listen in the hallways and use free online medical education" [1].

The hallmark of the medical profession is to deliver health care that is consistent with patients' needs within the modern health system [2]. Health care professionals are expected to stay abreast with recent medical developments, evolving health care standards and best clinical practice [3]. Information and communication technology has revolutionized the space of medical education [4]. Technologically agile pedagogical approaches that include the use of FOAM - Free Open Access Meducation (Medical Education) blogs - have dramatically advanced accessibility to continuous medical education globally [5].

FOAM originated in 2012 at the International Conference of Emergency Medicine in Dublin as a globally sourced and accessible educational resource to enhance traditional educational methodologies [6]. Over the years, there has been an increase in the number of Emergency Medicine and Critical Care blog databases with there being currently over 460 FOAM resources available [7].

FOAM provides an important medium for the sharing of ideas and fast-tracking the translation of medical developments into clinical practice [8]. It utilizes multiple online platforms such as podcasts, blogs, videos, tweets (Twitter), Facebook groups and other web-based media to develop and distribute medical education. These interactive databases have created a dynamic online community and a family of FOAM users 
worldwide [9]. Since FOAM leans towards self-directed problem-based learning, various medical schools across the world have also embedded it into their curriculum [10-12].

Despite the increasing popularity of FOAM globally, data relating to its awareness and usage in Africa is lacking. We therefore aimed to explore the awareness and usage of FOAM among doctors working at select emergency departments in Johannesburg.

\section{Materials And Methods}

This researcher-administered, questionnaire based, cross sectional study was conducted between 01 November 2017 and 31 January 2018. The study population comprised a convenience sample of 104 medical doctors working at the EDs of one of five hospitals in Johannesburg. All five hospitals were affiliated to the University of the Witwatersrand.

Questionnaires were distributed to potential participants (doctors) working at the respective EDs. Participants included emergency medicine physicians (EMPs), emergency medicine registrars (EMRs) and emergency medicine medical officers (MOs). Doctors registered to practice as specialists in the field of emergency medicine were classified as EMPs, whereas doctors that were training to become specialist in the field of emergency medicine were classified as EMRs. All other doctors who had completed their medical internship and were employed at each of the included hospitals EDs were classified as MOs. Medical interns and undergraduate students were excluded from the study.

After conducting a pilot study on five random subjects in July 2017, the final questionnaire was adapted from the questionnaire that was utilized in the study by Thurtle et al. [13]. The questionnaire assessed awareness and usage of FOAM, reasons for not using FOAM and devices used to access FOAM. In addition, the most popular FOAM blog used by study participants was also determined [8].

Ethical clearance to conduct the study was obtained from the Human Research Ethics Committee (Medical) of the University of the Witwatersrand (clearance certificate M170723). Further written approval was granted by the Chief Executive Officers and Heads of the Emergency Department of each of the participating hospitals.

The participant information sheet and questionnaire were distributed by the primary investigator to consenting participants at the respective departmental academic meetings. No identifying data was collected. The questionnaires were completed in confidence and returned into a sealed box that was provided.

Collected data was captured into an electronic data spread sheet (Microsoft ${ }^{\circledR}$ Excel $^{\circledR}$ ) and thereafter analyzed. Results were predominantly described using frequency and percentage tables and a graph. The Chi Square test was used to compare differences between the proportion of females and males that used FOAM blogs, while the Fisher's Exact test was used to compare the awareness and usage of FOAM between MOs, EMRs and EMPs. The level of significance was set at $\alpha=0.05$.

\section{Results}

Of the 129 potential subjects that were approached, 104 completed the survey, giving a response rate of $80.6 \%$. Fifty-one percent $(n=53)$ of respondents were female. Of the total number of respondents, MOs comprised 56.8\% ( $n=59)$, EMRs 28.8\% $(n=30)$ and EMPs $14.4 \%(n=15)$. Most of the respondents were aged between 31 and 39 years $(n=40,43.9 \%)$. All the EMRs were under the age of 50 years, while all the EMPs were older than 30 years.

Most participants ( $n=91,87.5 \%$ ) were aware of the existence of FOAM, however only one participant had started his own FOAM blog. Eighty-two (78.8\%) participants used FOAM while 13 (12.5\%) were unsure if they used FOAM and nine (8.7\%) did not use FOAM. Majority of those that used FOAM, only used it once a week $(\mathrm{n}=47,57.3 \%)$. There were no significant differences between the proportion of females $(\mathrm{n}=43)$ and males $(\mathrm{n}=39)$ that used FOAM $(\mathrm{p}=0.56)$. Smartphones were by far the most commonly used device to access FOAM $(\mathrm{n}=91,87.5 \%)$. Details of the above are described in Table 1 . 


\begin{tabular}{|c|c|c|c|}
\hline & MO (n, \%) & $\operatorname{EMR}(n, \%)$ & EMP $(n, \%)$ \\
\hline \multicolumn{4}{|l|}{ GENDER } \\
\hline Female $(n=53,51.0 \%)$ & $32(60.4)$ & $10(18.9)$ & $11(20.7)$ \\
\hline Male $(n=51,49.0 \%)$ & 27 (52.9) & 20 (39.2) & $4(7.9)$ \\
\hline \multicolumn{4}{|l|}{ AGE GROUP (YEARS) } \\
\hline$\leq 30(n=42,40.4 \%)$ & $34(80.9)$ & $8(19.1)$ & $0(0)$ \\
\hline $31-39(n=44,42.3 \%)$ & $15(34.1)$ & 19 (43.2) & $10(22.7)$ \\
\hline $40-49(n=11,10.6 \%)$ & $6(54.6)$ & $3(27.2)$ & $2(18.2)$ \\
\hline$\geq 50(n=7,6.7 \%)$ & $4(57.1)$ & $0(0)$ & $3(42.9)$ \\
\hline \multicolumn{4}{|l|}{ AWARENESS OF FOAM } \\
\hline Entire cohort $(n=91,87.5 \%)$ & 47 (51.6) & 29 (31.9) & $15(16.50)$ \\
\hline$\leq 30$ years $(\mathrm{n}=37,40.7 \%)$ & $29(78.4)$ & $8(21.6)$ & N/A \\
\hline $31-39$ years $(n=40,43.9 \%)$ & $12(30.0)$ & $18(45.0)$ & $10(25.0)$ \\
\hline $40-49$ years $(n=10,11.0 \%)$ & $5(50.0)$ & $3(30.0)$ & $2(20.0)$ \\
\hline$\geq 50$ years $(n=4,4.4 \%)$ & $1(25.0)$ & N/A & $3(75.0)$ \\
\hline \multicolumn{4}{|l|}{ USAGE OF FOAM } \\
\hline Entire cohort $(\mathrm{n}=82,78.8 \%)$ & $41(50.0)$ & $28(34.1)$ & $13(15.9)$ \\
\hline$\leq 30$ years $(n=31,37.8 \%)$ & 24 (77.4) & $7(22.6)$ & N/A \\
\hline $31-39$ years $(n=39,47.6 \%)$ & $12(30.8)$ & $18(46.1)$ & $9(23.1)$ \\
\hline $40-49$ years $(n=8,9.8 \%)$ & $4(50.0)$ & $3(37.5)$ & $1(12.5)$ \\
\hline$\geq 50$ years $(n=4,4.8 \%)$ & $1(25.0)$ & N/A & $3(75.0)$ \\
\hline \multicolumn{4}{|l|}{ FREQUENCY OF USAGE OF FOAM } \\
\hline Daily ( $n=24,29.3 \%)$ & $9(37.5)$ & $10(41.7)$ & $5(20.8)$ \\
\hline Weekly ( $\mathrm{n}=47,57.3 \%)$ & $24(51.0)$ & 17 (36.2) & $6(12.8)$ \\
\hline Monthly $(n=11,13.4 \%)$ & $8(72.7)$ & $1(9.1)$ & $2(18.2)$ \\
\hline \multicolumn{4}{|l|}{ DEVICES USED TO ACCESS FOAM } \\
\hline Smartphone ( $\mathrm{n}=91,87.5 \%)$ & $50(54.9)$ & $28(30.8)$ & $13(14.3)$ \\
\hline Tablet $(\mathrm{n}=37,35.6 \%)$ & 12 (32.4) & 15 (40.5) & 10 (27.1) \\
\hline Computer/Laptop ( $n=49,47.1 \%)$ & $22(44.9)$ & 17 (34.7) & $10(20.4)$ \\
\hline MP3/iPOD ( $n=2,1.9 \%)$ & $1(50.0)$ & $1(50.0)$ & $0(0)$ \\
\hline
\end{tabular}

TABLE 1: Description of gender, age group, awareness of FOAM, usage of FOAM, frequency of usage of FOAM and devices used to access FOAM among participants with various levels of training

MO: Medical Officers; EMR: Emergency Medicine Registrars; EMP: Emergency Medicine Physicians; N/A: Not applicable.

Awareness and usage of FOAM was significantly lower in MOs compared to EMRs $(p=0.024$ and $p=0.014$, respectively). There were no statistically significant differences between MOs and EPs ( $p=0.109$ and $p=$ 0.327 , respectively) or EMRs and EMPs $(\mathrm{p}=1.00$ and $\mathrm{p}=0.591$, respectively). Figure 1 describes the number of hours spent by participants per day on FOAM. Most participants spent between one and two hours per day on FOAM $(n=29,35.4 \%)$. 


\section{Cureus}

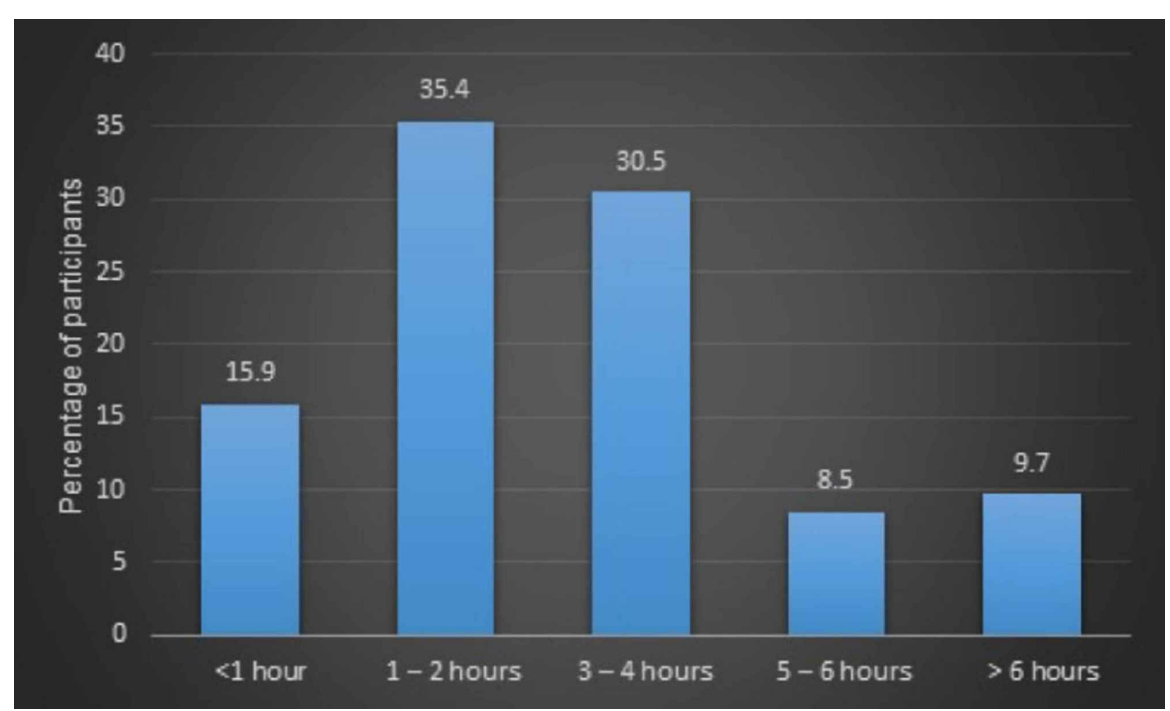

FIGURE 1: Hours spent per day on FOAM

Among the nine respondents that did not use FOAM, reasons included: unfamiliarity with social media $(\mathrm{n}=$ $4,44.4 \%)$; lack of time $(n=3,33.4 \%)$; lack of access to free internet in the department $(n=1,11.1 \%)$ and reluctance to use social media $(n=1,11.1 \%)$. Most of the participants $(n=83,79.9 \%)$ reported that a tutorial on how to access FOAM would increase their use of FOAM. More than three-quarter of subjects ( $\mathrm{n}=82$, $78.8 \%$ ) agreed that FOAM is an interactive tool, while $74(71.2 \%)$ agreed that FOAM encouraged collaboration within the medical community. The most popular FOAM blog among participants is described in Table 2.

\begin{tabular}{|l|l|l|}
\hline FOAM blog & Country of Origin & $\mathbf{n}(\%)$ \\
\hline Life in the Fast Lane & Australia & $67(73.6)$ \\
\hline EmCrit & USA & $8(8.8)$ \\
\hline Academic Life in Emergency Medicine & USA & $6(6.6)$ \\
\hline FOAM EM RSS & USA & $4(4.4)$ \\
\hline St Emlyn's & England & $2(2.2)$ \\
\hline The Skeptics Guide to Emergency Medicine & Canada & $2(2.2)$ \\
\hline Pulm CCM & USA & $1(1.1)$ \\
\hline Resus.me & USA & $1(1.1)$ \\
\hline Boring EM & Canada & $0(0)$ \\
The Trauma Professional's Blog & USA & $0(0)$ \\
\hline
\end{tabular}

\section{TABLE 2: Most popular FOAM blog among participants}

\section{Discussion}

It is rare to find a profession that has not been impacted by the digital revolution. The ubiquity and rapid increase in availability of digital media in the field of emergency medicine has led to calls for the formal integration of online learning into residency training programs [14]. FOAM has the potential to fill the gaps in medical training, especially in resource constrained economies [15].

Our data showed that FOAM awareness was widespread (87.5\%) among doctors at the studied emergency departments. This is in keeping with the findings of Thurtle et al. in 2015 who reported that $82 \%$ of emergency medicine doctors in both developed and low resource settings were aware that FOAM existed [13]. With regards to FOAM usage, Pearson et al. reported that $41 \%$ of respondents in their study placed a "low" or "very low" importance on the use of social media in emergency medicine, but rather preferred to use social media for their own personal use [16]. This trend could be changing as evidenced by our findings whereby more than three-quarter of respondents (78.8\%) indicated that they had used FOAM. The majority 
of study participants used FOAM on a weekly basis (57.3\%), which was much better than the findings of Thurtle et al., where most participants only used FOAM 1-2 times per month [13]. Due to its longer battery life, cost effectiveness and portability, it is not surprising that most study participants (87.5\%) accessed FOAM blogs using their smartphone [17].

Although females have been proven to be more proficient when it comes to the ease of use of social media, we did not find any significant differences between the proportion of females and males that used FOAM (p $=0.56$ ) [18]. Previous studies had shown that the reluctance by some healthcare providers (HCPs) to utilize FOAM as a learning tool was attributed to its lack of peer review, possible violation of patients' rights and information overload [19,20]. In contrast, reasons for not using FOAM among participants of this study included time constraints, lack of free Wi-Fi and unfamiliarity with social media.

There has been little study of the educational needs and time spent online by healthcare professionals in general [21]. While it is a known fact that the younger generation has readily adopted the use of technology to supplement their learning [22], increasing practitioner age (especially those older than 50 years) has been recognized as a barrier to the adoption of technologically driven health systems [23,24]. Brown et al. conducted a study on a random sample of doctors including EM doctors in Australia. They found that senior HCPs were not keen on making social media a part of their daily practice and did not subscribe to it despite the large amount of freely available information. The study further found that the extent of social media incorporation into daily practice differed greatly from individual to individual even within one hospital. The authors thought that this might be a result of limited online capabilities of senior healthcare practitioners in Australia [19]. The impact of age on the use of FOAM could not be assessed in our study as only four participants were aged older than 50 years. The lack of older doctors employed at the studied facilities may be attributed to the fact that emergency medicine is a relatively new specialty in South Africa [25]. In keeping with the findings of Burkholder et el., Life in the Fast Lane was also the most popular FOAM blog in this study [8]. EMCrit and Academic Life in Emergency Medicine have also been reported as popular emergency medicine FOAM blogs.

Low- and middle-income countries (LMIC) face many challenges in their medical training programs, one of them being a shortage of faculty staff [26]. FOAM has the potential to serve as a platform for the sharing of the latest medical information in these settings. Although EM trainees in both developed and LMIC were aware of the existence of FOAM, trainees in LMIC were less aware of specific FOAM resources [13]. Future research into FOAM usage in LMIC would be helpful to identify the gaps in educational resources and ascertain whether FOAM has the potential to mitigate this.

A limitation to our study findings is that this was a regional study that was conducted at only five hospitals in Johannesburg. Furthermore, all included facilities had an academic affiliation. Hence, our findings may not be representative of the awareness and usage of FOAM among emergency medicine doctors in general. Also, since this was a questionnaire-based study, self-reporting of data by respondents may have been subject to bias. Despite these limitations, this study has added to our understanding on the awareness and usage of FOAM in an African context. Hopefully, this study will inspire similar larger scale studies across a broader range of specialties.

\section{Conclusions}

The level of awareness of FOAM is high and its usage prevalent among emergency medicine healthcare professionals in Johannesburg. Smartphones stood out as the preferred device utilized to access FOAM, while Life in the Fast Lane was the most popular blog. The increasing rate of adoption of FOAM by healthcare professionals is a call for the conduction of larger studies and the formal incorporation of FOAM into training curricula.

\section{Additional Information \\ Disclosures}

Human subjects: Consent was obtained by all participants in this study. Human Research Ethics Committee (Medical) issued approval M170723. This study was unconditionally approved by the Human Research Ethics Committee (Medical) of the University of the Witwatersrand. Animal subjects: All authors have confirmed that this study did not involve animal subjects or tissue. Conflicts of interest: In compliance with the ICMJE uniform disclosure form, all authors declare the following: Payment/services info: All authors have declared that no financial support was received from any organization for the submitted work. Financial relationships: All authors have declared that they have no financial relationships at present or within the previous three years with any organizations that might have an interest in the submitted work. Other relationships: All authors have declared that there are no other relationships or activities that could appear to have influenced the submitted work.

\section{References}

1. What is FOAMed?. (2019). Accessed: August 12, 2019: https://www.aaemrsa.org/get-involved/foamed.

2. Salmond SW, Echevarria M: Healthcare transformation and changing roles for nursing. Orthop Nurs. 2017, 36:12-25. 10.1097/NOR.0000000000000308

3. Sherbino J, Frank JR, Snell L: Defining the key roles and competencies of the clinician-educator of the 21st century: a national mixed-methods study. Acad Med. 2014, 89:783-789. 10.1097/ACM.0000000000000217 
4. Masic I, Pandza H, Toromanovic S, Masic F, Sivic S, Zunic L, Masic Z: Information technologies (ITs) in medical education. Acta Inform Medica. 2011, 19:68-78. 10.5455/aim.2011.19.161-167

5. Holmboe E, Cassel C: Continuing medical education and maintenance of certification: essential links . Perm J. 2007, 11:71-75. 10.7812/TPP/07-090

6. FOAM. (2019). Accessed: September 29, 2019: https://litfl.com/foam-free-open-access-medical-education/.

7. FOAM EMCC Blogs 2018. (2019). Accessed: September 22, 2019: https://litfl.com/foam-emcc-blogs-2018/.

8. Burkholder T, Bellows J, King R: Free open access medical education (FOAM) in emergency medicine: the global distribution of users in 2016. West J Emerg Med. 2018, 19:600-605. 10.5811/westjem.2018.3.36825

9. How FOAM is revolutionizing medical education. (2018). Accessed: August 3, 2019: https://healthydebate.ca/2018/05/topic/foam-medical-education.

10. Rowe M, Frantz J, Bozalek V: Beyond knowledge and skills: the use of a Delphi study to develop a technology-mediated teaching strategy. BMC Med Educ. 2013, 13:51. 10.1186/1472-6920-13-51

11. Keenan ID, Slater JD, Matthan J: Social media: insights for medical education from instructor perceptions and usage. MedEdPublish. 2018, 7:10.15694/mep.2018.0000027.1

12. Cevik AA, Aksel G, Akoglu H, Eroglu SE, Dogan NO, Altunci YA: Social media, FOAMed in medical education and knowledge sharing: local experiences with international perspective. Turkish J Emerg Med. 2016, 16:112-117. 10.1016/j.tjem.2016.07.001

13. Thurtle N, Banks C, Cox M, Pain T, Furyk J: Free open access medical education resource knowledge and utilisation amongst emergency medicine trainees: a survey in four countries. African J Emerg Med. 2016, 6:12-17. 10.1016/j.afjem.2015.10.005

14. Wittich CM, Agrawal A, Cook DA, et al.: E-learning in graduate medical education: survey of residency program directors. BMC Med Educ. 2017, 17:114. 10.1186/s12909-017-0953-9

15. Hodkinson PW, Wallis LA: Emergency medicine in the developing world: a Delphi study . Acad Emerg Med. 2010, 17:765-774. 10.1111/j.1553-2712.2010.00791.x

16. Pearson D, Bond M, Kegg J, et al.: Evaluation of social media use by emergency medicine residents and faculty. West J Emerg Med. 2015, 16:715-720. 10.5811/westjem.2015.7.26128

17. Computer vs. smartphone. (2018). Accessed: August 18, 2019: https://www.computerhope.com/issues/ch001398.htm\#targetText=Smartphones and tablets have less,like a desktop computer....

18. The effects of gender on the adoption of social media: an empirical investigation . (2017). Accessed: August 16, 2019: https://www.researchgate.net/publication/319130496_The_Effects_of_Gender_On_Social_Media_Adoption_The_Effects_of_Ger

19. Brown J, Ryan C, Harris A: How doctors view and use social media: a national survey . J Med Internet Res. 2014, 16:267. 10.2196/jmir.3589

20. O’Doherty D, Dromey M, Lougheed J, Hannigan A, Last J, McGrath D: Barriers and solutions to online learning in medical education - an integrative review. BMC Med Educ. 2018, 18:130. 10.1186/s12909-0181240-0

21. Jahanshir A, Karimialavijeh E, Sheikh H, Vahedi M, Momeni M: Smartphones and medical applications in the emergency department daily practice. Emergency. 2017, 5:e14.

22. Irfan KS, Farhana I, Eiad AF, et al.: Family physicians' utility of social media: a survey comparison among family medicine residents and physicians. Afr Health Sci. 2018, 18:817. 10.4314/ahs.v18i3.41

23. Huff JS, Melnick ER, Tomaszewski CA, Thiessen MEW, Jagoda AS, Fesmire FM: Clinical policy: critical issues in the evaluation and management of adult patients presenting to the emergency department with seizures. Ann Emerg Med. 2014, 63:437-447. 10.1016/j.annemergmed.2014.01.018

24. Dr Anton Prinsloo: on connecting doctors and eHealth . (2015). Accessed: August 17, 2019: https://ehealthnews.co.za/anton-prinsloo/.

25. Wallis LA, Garach SR, Kropman A: State of emergency medicine in South Africa . Int J Emerg Med. 2008, 1:69-71. 10.1007/s12245-008-0033-3

26. Kinfu Y, Dal Poz MR, Mercer H, Evans DB: The health worker shortage in Africa: are enough physicians and nurses being trained?. Bull World Health Organ. 2009, 87:225-230. 10.2471/BLT.08.051599 